\title{
Proteomics: a promising tool for research on sex-related differences in dioecious plants
}

\author{
Le Yang ${ }^{\dagger}$, Fangping Gong ${ }^{\dagger}$, Erhui Xiong and Wei Wang * \\ State Key Laboratory of Wheat and Maize Crop Science, Collaborative Innovation Center of Henan Grain Crops, College of \\ Life Science, Henan Agricultural University, Zhengzhou, China
}

Keywords: dioecious plants, proteomics, molecular biomarkers, sex determination, proteins associated with sex, sex related differences

Dioecy is a form of sex distribution in seed plants. In dioecious plants, the male and female reproductive organs sit on different unisexual plants. Dioecy occurs in many plant families, and approximately 14,600 species in 200 families are dioecious (Ming et al., 2007); however, a limited number of dioecious plants have evolved sex chromosomes (Negrutiu et al., 2001; Vyskot and Hobza, 2004). For plants without obvious sex chromosomes, genetic sex determination may be due to a single locus or multiple loci either unlinked or tightly linked on autosomes (Divashuk et al., 2014; Razumova et al., 2015). A complex sex determination mechanism has been found in Mercurialis annua, in which the sex is controlled by multiple unlinked loci (Janousek and Mrackova, 2010). Recently, much research on dioecious plants has focused on sex-linked genes (e.g., Blavet et al., 2015; Harkess et al., 2015; Jia et al., 2015) and sex-related differences (e.g., Chen et al., 2011, 2013; Zhou et al., 2012; Liu et al., 2013; Xiong et al., 2013; Juvany et al., 2014; Deng et al., 2015; Juvany and Munné-Bosch, 2015).

The research on sex-related differences in dioecious plants has the potential to explore the evolutionary, developmental and molecular processes leading to sex differentiation (Diggle et al., 2011) and sex chromosome evolution (Charlesworth, 2015). Unlike animals, most dioecious plants do not exhibit discernible sexual dimorphism prior to sexual maturity. In practice, the economic values often differ between male and female plants. In practice, male plants have an advantage over females in providing edible stems (e.g., asparagus, Deng et al., 2015; Harkess et al., 2015) and fibers (e.g., hemp, Divashuk et al., 2014; Razumova et al., 2015), whereas female plants are commonly cultivated for fruits (e.g., Myrica rubra, Jia et al., 2015) and seeds (e.g., Pistacia chinensis, Xiong et al., 2013). Therefore, a reliable method for sex identification at the juvenile stage would greatly benefit breeding programs for dioecious plants.

Proteomics represents a powerful tool for protein identification and gene functional analysis. In proteomic analyses, proteins are first separated using gel-based (typically 2-DE) or gel-free approaches, followed by mass spectrometry (MS). Both gel-based approaches (e.g., 2-DE) and gel-free approaches (e.g., iTRAQ) are frequently used for proteomic analysis. The aim of most proteomics analyses is to maximize the number of polypeptides that can be resolved, particularly for comparative proteomics, which generally involves identifying minor differences between experimental and control samples. In this regard, 2-DE-based proteomic analysis is particularly suitable for the paired comparison of dioecious plants. In this paper, we take a practical look at the value and the limitations of proteomic approaches for research on sex-related differences in dioecious plants.

In dioecious plants, females often invest more in reproduction and less in growth and maintenance compared to males (Barrett, 2015). This differential investment between sexes may result in distinct growth patterns (Cepeda-Cornejo and Dirzo, 2010) and sex-biased responses to environmental stresses (Xu et al., 2007; Juvany et al., 2014). Thus, it is speculated that the differences 
between males and females would be displayed at the protein expression level, which is the basis of the proteomic analyses of sex determination and sex-relate differences in dioecious plants. Proteomic differences are also dependent on developmental stages and environmental conditions, so experimental design is an important component. While differential abundant protein analysis has been applied to investigate sex-related differences in dioecious plants, there are only a few studies that have used proteomic approaches (e.g., Chen et al., 2011, 2013; Xiong et al., 2013).
With respect to sex determination in dioecious plants (Figure 1), to our knowledge, Bracale et al. (1990) were the first to use 2-DE to compare the differences between male and female flowers of the dioecious plant Asparagus officinalis; they found that the flowers exhibit a distinct set of specific proteins, some of which differed between sexes. Golan-Goldhirsh et al. (1998) analyzed differentially accumulated proteins in the inflorescence buds of Pistacia vera using SDS-PAGE and immunoblotting. They found that a $32 \mathrm{kDa}$ glycoprotein is related to flower development and flowering in both sexes and that a $27 \mathrm{kDa}$

A

\begin{tabular}{|c|c|c|c|c|}
\hline Species & Materials & Methods & Sex associated proteins & References \\
\hline $\begin{array}{l}\text { Asparagus } \\
\text { officinalis }\end{array}$ & Flowers & 2-DE & Specific proteins present in both sexes & Bracale et al. 1990 \\
\hline Pistaciavera & $\begin{array}{l}\text { Inflorescence } \\
\text { buds }\end{array}$ & SDS-PAGE & A $27 \mathrm{kDa}$ glycoprotein specific to the female & $\begin{array}{l}\text { Golan-Goldhirsh et } \\
\text { al. } 1998\end{array}$ \\
\hline Actinidia & Leaves & SDS-PAGE & $\begin{array}{l}\text { An } 18 \mathrm{kDa} \text { protein specific to the male; a } 67 \mathrm{kDa} \\
\text { protein specific to the female }\end{array}$ & $\begin{array}{l}\text { Khukhunaishvili } \\
\text { \&Dzhokhadze } 2006\end{array}$ \\
\hline Ginkgo biloba & Inflorescences & SDS-PAGE & $\begin{array}{l}\text { A } 28 \mathrm{kDa} \text { protein specific to the male; a } 36 \mathrm{kDa} \\
\text { protein and a } 92 \mathrm{kDa} \text { protein specific to the female }\end{array}$ & Yang and Fu 2012 \\
\hline \multirow{3}{*}{$\begin{array}{l}\text { Pistaciachinens } \\
\quad \text { is }\end{array}$} & Leaves & \multirow{3}{*}{ 2-DE, MS/MS } & $\begin{array}{l}\text { The abundance of NB-ARC domain containing } \\
\text { protein and light harvesting chlorophyll a/b- } \\
\text { binding protein are higher in the male than in the } \\
\text { female }\end{array}$ & \multirow{3}{*}{ Xiong et al. 2013} \\
\hline & Stem phloems & & $\begin{array}{l}\text { Eukaryotic translation initiation factor } 5 \mathrm{~A} 2 \text {, } \\
\text { phosphoglycerate kinase } 2 \text { and an expressed } \\
\text { protein accumulate in higher abundance in the } \\
\text { female; temperature-induced lipocalin is more } \\
\text { abundant in the male }\end{array}$ & \\
\hline & Stem xylems & & $\begin{array}{l}\text { Ascorbate peroxidase and temperature-induced } \\
\text { lipocalin accumulate in higher abundance in the } \\
\text { female than in the male }\end{array}$ & \\
\hline
\end{tabular}

B

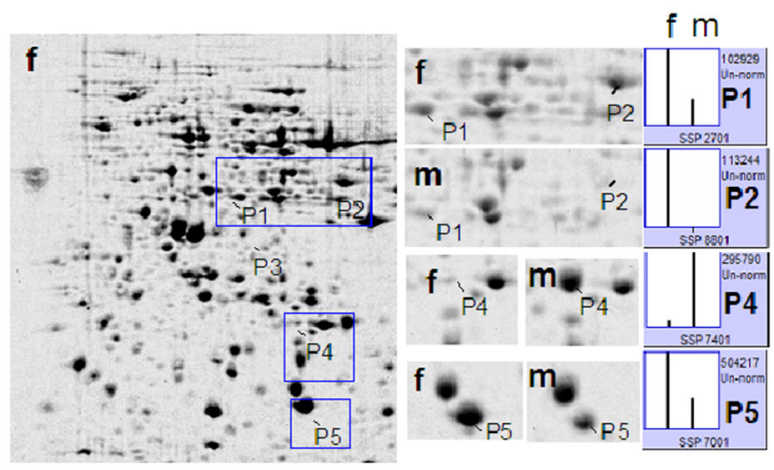

C

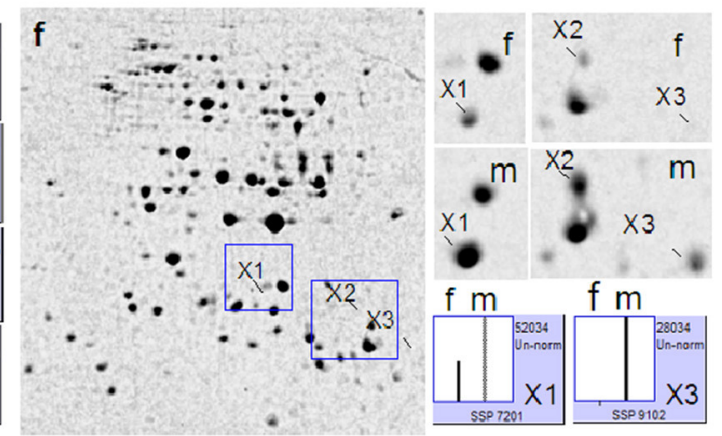

FIGURE 1 | Characterization of differentially abundant sex-related proteins in dioecious plants. (A) Summary of several studies. (B,C), 2-DE analysis of differentially abundant proteins in stem phloem (B) and xylem (C) between male and female plants in Pistacia chinensis (Xiong et al., 2013). A 2-DE map of female plants was used as a reference. Magnified gel regions containing differentially abundant spots were accompanied by a column configuration of relative abundance (generated via PDQUEST). The two sex-related proteins were further examined in individual plants and the results were reproducible. P1, eukaryotic translation initiation factor; P2, phosphoglycerate kinase; P5, uncharacterized protein; X1, ascorbate peroxidase; P4 and X3, temperature-induced lipocalin. P3 and X2 were not identified. f, female; $m$, male. 
glycoprotein is specific to females. In two species of Actinidia, SDS-PAGE analysis revealed specific proteins in the leaves of male and female plants: an intense band of approximately $18 \mathrm{kDa}$ was specific to males, whereas an intense band of approximately $67 \mathrm{kDa}$ was specific to females (Khukhunaishvili and Dzhokhadz, 2006). Differential abundant protein analysis can provide important clues in sex determination in dioecious plants, particularly in the expression of sex-related genes. Unfortunately, the above proteins were not actually identified in these studies due to technical or other limitations.

P. chinensis is a strict dioecious plant in the cashew family. In $P$. chinensis, male and female plants strictly maintain their respective sexual phenotypes and an approximately 1:1 sex ratio (Yu and Lu, 2011), which suggests the presence of a clear genetic basis of sex differences. This small tree or shrub is widely planted in China for biodiesel oil due to its high seed oil content (Wang and Liu, 2011). Thus, female plants of $P$. chinensis have a higher economic value than male plants. However, there are still no reliable physiological, biochemical, and molecular methods for sex identification during the long juvenile stage of this species. A similar situation exists in dioecious M. rubra (Chinese bayberry, Jia et al., 2015), which is an important subtropical evergreen fruit tree in southern China and Southeast Asia. Recently, we analyzed the proteomic differences associated with sex in $P$. chinensis using a 2-DE/MS-MS approach (Xiong et al., 2013). Vegetative organs (leaf and stem) of $P$. chinensis, rather than reproductive organs/tissues, were used for proteomic analysis to develop potential protein markers that can be used at the juvenile stage. Proteins from leaf, stem xylem and stem phloem were used for comparative analysis (Figure 1). Ten differential protein spots between male and female plants in $P$. chinensis were found to be reproducible, and of these ten, seven were identified via MS/MS and BLAST analysis. In particular, phosphoglycerate kinase was present in high abundance in the stem phloem in females; however, very little was detected in the males. Temperatureinduced lipocalin was highly abundant in the stem xylem and stem phloem in male plants, whereas it was less abundant in female plants (Xiong et al., 2013). The abundance differences of both proteins were further confirmed in 10 individuals, sampled in autumn or in winter, indicating that they may be promising molecular marker candidates for sex determination in P. chinensis.

With respect to sex-related differences in dioecious plants, proteomic approach are also powerful tool when used for protein profiling differences between males and females. The Populus genus includes six dioecious species, which are all agriculturally and ecologically important trees. Abiotic stress (e.g., salinity, $\mathrm{Mn}$, and Cd) is a major limiting factor for poplar growth. The completion of the Populus trichocarpa genome (Tuskan et al., 2006) has facilitated proteomic analysis of abiotic stress response in poplar trees. Recently, differences in the leaf proteomes of male and female Populus cathayana plants under excess salt (Chen et al., 2011) and Mn (Chen et al., 2013) were compared using a 2-DE/MS-MS approach. The study found that many important functional proteins are present at higher levels and there were reductions in protein degradation in males under stress conditions. Obviously, results obtained from proteomic analyses can facilitate further understandings of different management strategies of cellular activities in male and female plants, and provide gene targets for genetic manipulation of poplar tolerance to abiotic stresses.

The accurate identification and functional analysis of proteins is strongly linked to the quality and availability of the genome sequence. The majority of dioecious plants are non-model organisms with no available genome, with the exception of $P$. trichocarpa. Thus, a major limitation in proteomic analysis of sex determination in dioecious plants is the small amount of gene sequences available in public databases. The identifications of proteins from plant species with unknown genome sequences are acceptable only if MS/MS-derived peptide sequences have been used for database searching or BLAST analysis. Generally, fragment spectra should only be assigned to a peptide if the predictive value (score) is high, and such a workflow should be strictly adopted for species without a genome sequence. In the case of $P$. chinensis, six functional proteins were identified according to their high matches to homologs from Oryza sativa, Arabidopsis thaliana, Pennisetum americanum, Ricinus communis, Solanum lycopersicum, Tamarix androssowii, and Vitis vinifera (Xiong et al., 2013). Wherever possible, DNA, ESTs or protein sequences from a closely related organism should be used if the number of available sequences is low.

Despite the methodology being a relatively new, proteomics can be the method of choice to make a high-throughput discovery of sex-related differences in dioecious plants. Proteomic results can supplement and verified using physiological and molecular analyses of dioecious plants. Most importantly, the protein (particularly enzyme) information obtained via proteomic approaches provides useful clues to sex determination mechanisms and the development of molecular and biochemical detection methods for sex identification in dioecious plants. Finally, although post-genomic studies of dioecious plants is still in its infancy, continued integration of discovery-driven approaches (e.g., transcriptomics, genomics, proteomics, and metabonomics) can and will lead to unprecedented rates of information discovery in sex-linked genes and sex-related differences in dioecious plants.

\section{ACKNOWLEDGMENTS}

We thank Dr. Joshua Heazlewood for copy-editing our manuscript. We acknowledge the financial support of the Program for Innovative Research Team (in Science and Technology) in University of Henan Province (Grant No. 15IRTSTHN015). 


\section{REFERENCES}

Barrett, S. C. (2015). Influences of clonality on plant sexual reproduction. Proc. Natl. Acad. Sci. U.S.A. 112, 8859-8866. doi: 10.1073/pnas.1501712112

Blavet, N., Blavet, H., Muyle, A., Käfer, J., Cegan, R., Deschamps, C., et al. (2015). Identifying new sex-linked genes through BAC sequencing in the dioecious plant Silene latifolia. BMC Genomics 16:546. doi: 10.1186/s12864-0151698-7

Bracale, M., Galli, M. G., Falavigna, A., and Soave, C. (1990). Sexual differentiation in Asparagus officinalis L. II. Total and newly synthesized proteins in male and femal flowers. Plant Reprod. 3, 23-30.

Cepeda-Cornejo, V., and Dirzo, R. (2010). Sex-related differences in reproductive allocation, growth, defense and herbivory in three dioecious neotropical palms. PLoS ONE 5:e9824. doi: 10.1371/journal.pone.0009824

Charlesworth, D. (2015). Plant contributions to our understanding of sex chromosome evolution. New Phytol. 208, 52-65. doi: 10.1111/nph. 13497

Chen, F., Zhang, S., Jiang, H., Ma, W., Korpelainen, H., and Li, C. Y. (2011). Comparative proteomics analysis of salt response reveals sex-related photosynthetic inhibition by salinity in Populus cathayana cuttings. J. Proteome Res. 10, 3944-3958. doi: 10.1021/pr200535r

Chen, F., Zhang, S., Zhu, G., Korpelainen, H., and Li, C. (2013). Populus cathayana males are less affected than females by excess manganese: comparative proteomic and physiological analyses. Proteomics 13, 2424-2437. doi: 10.1002/pmic.201200365

Deng, C. L., Wang, N. N., Li, S. F., Dong, T. Y., Zhao, X. P., Wang, S. J., et al. (2015). Isolation of differentially expressed sex genes in garden asparagus using suppression subtractive hybridization. J. Plant Res. 128, 829-838. doi: 10.1007/s10265-015-0735-6

Diggle, P. K., Di Stilio, V. S., Gschwend, A. R., Golenberg, E. M., Moore, R. C., Russell, J. R. W., et al. (2011). Multiple developmental processes underlie sex differentiation in angiosperms. Trends Genet. 27, 368-376. doi: 10.1016/j.tig.2011.05.003

Divashuk, M. G., Alexandrov, O. S., Razumova, O. V., Kirov, I. V., and Karlov, G. I. (2014). Molecular cytogenetic characterization of the dioecious Cannabis sativa with an XY chromosome sex determination system. PLoS ONE 9:e85118. doi: 10.1371/journal.pone.0085118

Golan-Goldhirsh, A., Peri, I., Birk, Y., and Smirnoff, P. (1998). Inflorescence bud proteins of Pistacia vera. Trees 12, 415-419. doi: 10.1007/pl00009725

Harkess, A., Mercati, F., Shan, H. Y., Sunseri, F., Falavigna, A., and Leebens-Mack, J. (2015). Sex-biased gene expression in dioecious garden asparagus (Asparagus officinalis). New Phytol. 207, 883-892. doi: 10.1111/nph.13389

Janousek, B., and Mrackova, M. (2010). Sex chromosomes and sex determination pathway dynamics in plant and animal models. Biol. J. Linn. Soc. 100, 737-752. doi: 10.1111/j.1095-8312.2010.01470.x

Jia, H. M., Jiao, Y., Wang, G. Y., Li, Y. H., Jia, H. J., Wu, H. X., et al. (2015). Genetic diversity of male and female Chinese bayberry (Myrica rubra) populations and identification of sex-associated markers. BMC Genomics 16:394. doi: 10.1186/s12864-015-1602-5

Juvany, M., Müller, M., Pintó-Marijuan, M., and Munné-Bosch, S. (2014). Sexrelated differences in lipid peroxidation and photoprotection in Pistacia lentiscus. J. Exp. Bot. 65, 1039-1049. doi: 10.1093/jxb/ert446
Juvany, M., and Munné-Bosch, S. (2015). Sex-related differences in stress tolerance in dioecious plants: a critical appraisal in a physiological context. J. Exp. Bot. 66, 6083-6092. doi: 10.1093/jxb/erv343

Khukhunaishvili, R. G., and Dzhokhadz, D. I. (2006). Electrophoretic study of the proteins from actinidia leaves and sex identification. Appl. Biochem. Microbiol. 42, 107-110. doi: 10.1134/S0003683806010170

Liu, J., Yin, T., Ye, N., Chen, Y., Yin, T., Liu, M., et al. (2013). Transcriptome analysis of the differentially expressed genes in the male and female shrub willows (Salix suchowensis). PLoS ONE 8:e60181. doi: 10.1371/journal.pone. 0060181

Ming, R., Wang, J., Moore, P. H., and Paterson, A. H. (2007). Sex chromosomes in flowering plants. Am. J. Bot. 94, 2141-2150. doi: 10.3732/ajb.94.2.141

Negrutiu, I., Vyskot, B., Barbacar, N., Georgiev, S., and Moneger, F. (2001). Dioecious plants: a key to the early events of sex chromosome evolution. Plant Physiol. 127, 1418-1424. doi: 10.1104/pp.010711

Razumova, O. V., Alexandrov, O. S., Divashuk, M. G., Sukhorada, T. I., and Karlov, G. I. (2015). Molecular cytogenetic analysis of monoecious hemp (Cannabis sativa L.) cultivars reveals its karyotype variations and sex chromosomes constitution. Protoplasma. doi: 10.1007/s00709-015-0851-0. [Epub ahead of print].

Tuskan, G. A., Difazio, S., Jansson, S., Bohlmann, J., Grigoriev, I., Hellsten, U., et al. (2006). The genome of black cottonwood, Populus trichocarpa (Torr. \& Gray). Science 313, 1596-1604. doi: 10.1126/science.1128691

Vyskot, B., and Hobza, R. (2004). Gender in plants: sex chromosomes are emerging from the fog. Trends Genet. 20, 432-438. doi: 10.1016/j.tig.2004.06.006

Wang, X. R., and Liu, W. Z. (2011). Development of oil bodies in the fruit of Pistacia chinensis. Chin. Bullet. Bot. 46, 665-674. doi: 10.3724/SP.J.1259.2011.00665

Xiong, E., Wu, X., Shi, J., Wang, X., and Wang, W. (2013). Proteomic identification of differentially expressed proteins between male and female plants in Pistacia chinensis. PLoS ONE 8:e64276. doi: 10.1371/journal.pone.0064276

Xu, X., Yang, F., Yin, C. Y., and Li, C. Y. (2007). Research advances in sex-specific responses in dioecious plants to environmental stresses. Chin. J. Appl. Ecol. 18, 2626-2631. (in Chinese).

Yu, L., and Lu, J. B. (2011). Does landscape fragmentation influence sex ratio of dioecious plants? A case study of Pistacia chinensis in the thousand-island region of China. PLoS ONE 6:e22903. doi: 10.1371/journal.pone.0022903

Zhou, Y. J., Xue, J. G., Wang, X. G., and Zhang, X. Q. (2012). Changes in inflorescence protein during advanced stages of floret development in Buchloe dactyloides (Poaceae). Genet. Mol. Res. 11, 3923-3932. doi: 10.4238/2012.August.17.5

Conflict of Interest Statement: The authors declare that the research was conducted in the absence of any commercial or financial relationships that could be construed as a potential conflict of interest.

Copyright (c) 2015 Yang, Gong, Xiong and Wang. This is an open-access article distributed under the terms of the Creative Commons Attribution License (CC BY). The use, distribution or reproduction in other forums is permitted, provided the original author(s) or licensor are credited and that the original publication in this journal is cited, in accordance with accepted academic practice. No use, distribution or reproduction is permitted which does not comply with these terms. 